\title{
The Manufacture of Hot-Compacted Layered Composite Systems Made of Oriented Semifinished PP-Films
}

\author{
Björn Rohde, ${ }^{1}$ Andrea Wibbeke, ${ }^{2}$ Hans-Peter Heim, ${ }^{1}$ and Volker Schöppner ${ }^{2}$ \\ ${ }^{1}$ Institute for Materials Engineering-Polymer Technology, University of Kassel, Moenchebergstraße 3, 34125 Kassel, Germany \\ ${ }^{2}$ Polymer Engineering Paderborn-Polymer Processing, University of Paderborn, Warburger Street 100, 33098 Paderborn, Germany
}

Correspondence should be addressed to Björn Rohde; bjoern.rohde@uni-kassel.de

Received 10 December 2013; Accepted 17 January 2014; Published 4 March 2014

Academic Editors: Y. Chen, K.-h. Nitta, and S. Yamazaki

Copyright (C) 2014 Björn Rohde et al. This is an open access article distributed under the Creative Commons Attribution License, which permits unrestricted use, distribution, and reproduction in any medium, provided the original work is properly cited.

Monoaxial stretched PP-films are used for the manufacture of hot-compacted layered composites. These are layered with stretched co-extruded coupling agent films, and are consolidated to laminates by means of a hot-compaction process, which employs pressure and temperature. This paper aims to examine the influence of the process settings on the properties of the composites during the hot-compaction process. For this purpose, the mechanical values will be determined by means of tensile testing variously compacted and configured layered film composites.

\section{Introduction and Fundamentals}

In regards of their morphological properties, self-reinforced composite materials display an exceptionally good mechanical property profile [1]. The incorporation of a selfreinforcement leads to a high orientation of the molecule chains, enabling a utilization of the high covalent bonding forces for reinforcement [2]. This orientation of the molecules induces an anisotropy which makes a manifold increase of the mechanical properties, that is, stiffness and strength [3], possible in comparison to injection molded basic material [4]. Due to the fact that the matrix and reinforcement fibers of self-reinforced composite systems are made of an identical basic material $[5,6]$, recycling these material systems is very simple [1]. Moreover, self-reinforced composite systems have a high lightweight potential because of their low density ( $\rho_{\mathrm{PP}}$ $\left.=0.91 \mathrm{~g} / \mathrm{cm}^{3}\right)$. In contrast to conventionally fiber-reinforced components, such as polymer systems with a relatively heavy glass fiber reinforcement $\left(\rho_{\mathrm{GF}}=2.5 \mathrm{~g} / \mathrm{cm}^{3}\right)$, low component wall strengths can be achieved at a low composite density owing to the high property level [1].

The basis for the creation of self-reinforcement is founded upon two basic principles. First, it is based upon the macromolecular orientations which are incorporated in the polymer. Second, it depends upon the generation of directed crystalline structures [7]. The deliberately induced deformation of the polymer in both the melt and solid phases enables a transfer of the two principles, however, with varying effects on the morphology.

The stretch and shear flows in the melt liquid phase cause an orientation of the macromolecules in the direction of the flow [8]. For example, stretch flows occur due to tapering the flow channel in form of a nozzle (Figure 1). The flow velocity of the melt increases as a result of a reduction of the nozzle cross section, leading to an alignment of the molecule chains in flow direction. If suitable thermic and rheological conditions are on hand, the development of needle crystals in the melt occurs [8].

These needle crystals act as nucleating agents in the calibration zone and initiate the epitaxial crystallization of folded lamellae. This structure, which is created in the melt liquid phase, is referred to as a shish kebab structure and is the characteristic feature of self-reinforced materials [7]. The "shishs" are attributed to the needle crystals that develop due to the flow and grow on the folded lamellae in the form of so-called "kebabs." By increasing the pressure (pressure solidification) while simultaneously cooling, this condition is frozen into place.

Another method which aims to increase the orientation degree in the polymer is monoaxial stretching, which 


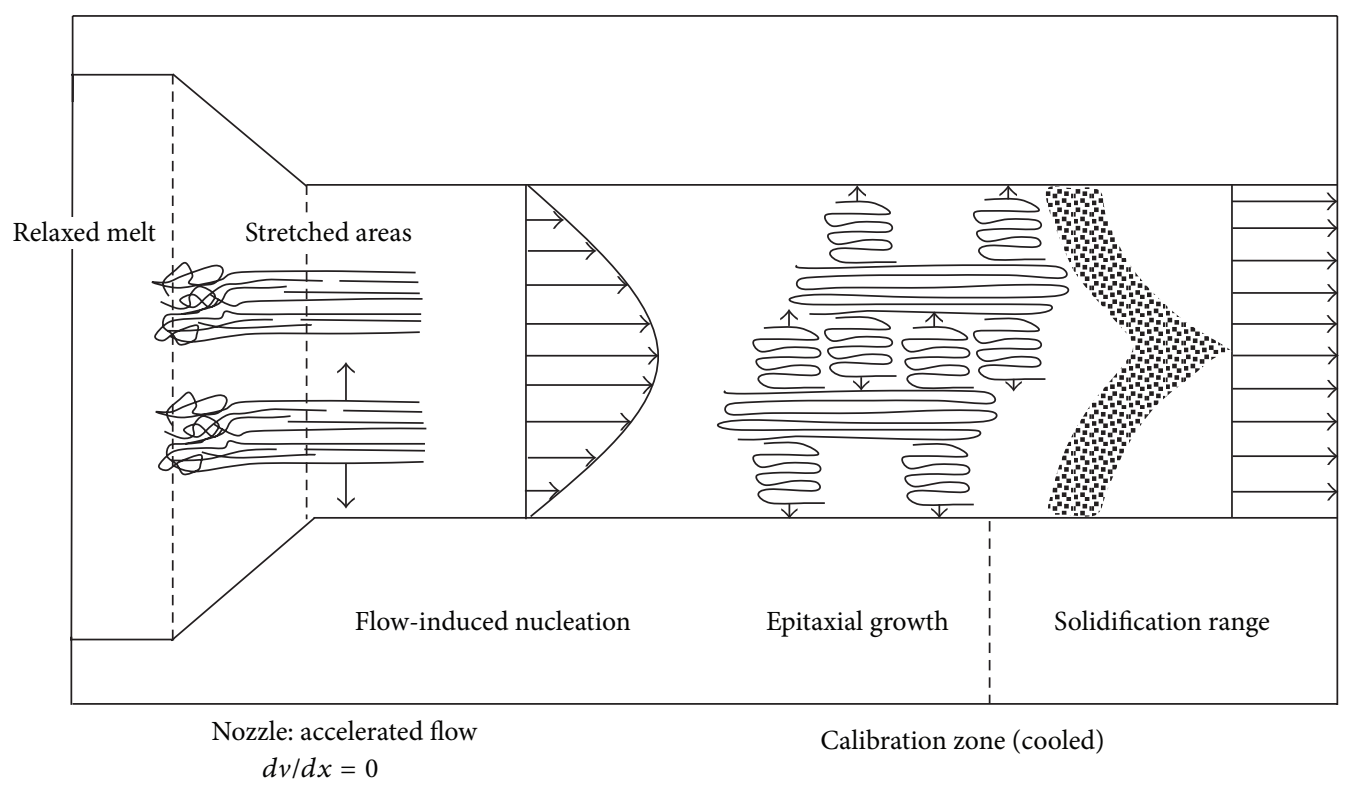

FiguRE 1: Macromolecular orientation according to [8].

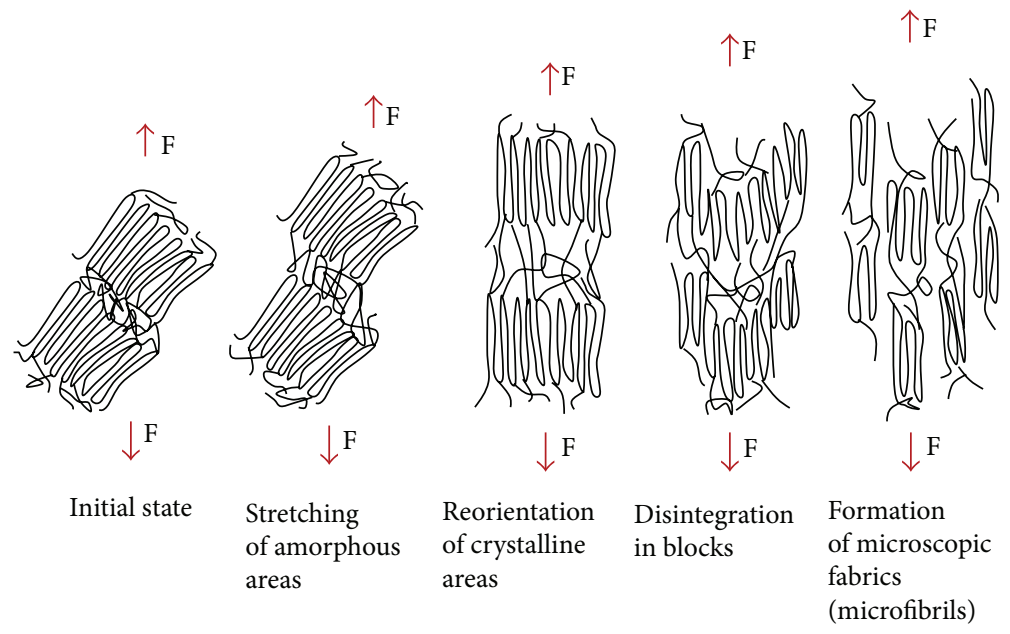

FIGURE 2: Stretching of a semicrystalline thermoplast in accordance with [11].

corresponds to a solid phase deformation [9]. Thermoplastic polymers, especially semicrystalline films, tapes, and fibers, are oriented at a temperature below the melt temperature using a rolling system with rollers rotating at different speeds [10]. Thus, particularly the amorphous areas in the direction of stretching are oriented. Consequently, an enhancement of the mechanical values, that is, stiffness and strength, occurs. Figure 2 illustrates the behavior of semicrystalline thermoplasts in regards to their molecule structure during stretching at a temperature that is slightly below the melt temperature of crystallite. The deformation begins in the amorphous regions. However, as the stretching increases, the semicrystalline areas orient themselves in the direction of loading. If the stretching is further increased, the crystalline areas disintegrate into blocks [11].

Due to the fact that self-reinforcement can only be applied to the direct manufacture of components to a limited extent, an intermediate step which uses layered, self-reinforced tape fabrics, fleeces, or films is added [5]. The consolidation of the layered semifinished materials is completed using a hot-compaction process, utilizing the factors temperature, pressure, and time. Here, the semifinished materials are consolidated into laminates. The self-reinforced, semifinished materials usually have a polypropylene basis and are commercially available. Self-reinforced, semifinished materials must be categorized into two essential types in accordance with their material concept.

The so-called coextrudates, for example, the high performance PP tape fabric "Pure" produced by Lankhorst, The Netherlands, have a three-layer configuration of woven tapes. By means of a coextrusion process, marginal, external layers made of a PP copolymer are extruded onto the self-reinforced $\mathrm{PP}$ polymer core [12]. This copolymer has a $10^{\circ} \mathrm{C}$ lower melting point than the core polymer, which develops the 
matrix phase during hot-compaction. The self-reinforcement is preserved for the most part if a processing temperature lower than the melt temperature of the core polymer is used.

The second material group consists of the monoextrudates, which are commercially available as geotextiles in form of tape fabrics and fleece systems. In contrast to coextrudates, this group consists of a single material structure [13]. This means that the semifinished products made of self-reinforced fibers, films, and tapes consist of a homogeneous polymer (often PP) when examining the cross section. A matrix must be generated out of the reinforcement tape during the hot-compaction process because the monoextrudates do not possess a preconfigured matrix generating layer [9]. Selective melting of the layered reinforcement fibers, tapes, or films with a short period of overheating above the melt temperature helps to develop the matrix phase of monoextrudates. Here, the partial loss of the self-reinforcement is a negative effect, which is inevitably induced by the development of the matrix. Monoextruded material systems compensate this disadvantage thanks to their simple structures, making it possible to keep manufacturing costs low while still offering good composite properties.

An essential advantage is the monomaterial characteristic of self-reinforced composite systems. These so-called Single Polymer Composites (SPC) do not implement any foreign fibers for reinforcement, such as glass, carbon, aramid, or natural fibers $[5,14]$. The reinforcement is solely based on the utilization of the high chemical bonding forces in the macromolecules, which are obtained by means of their orientation in the melt and solid polymer phases [7]. For this reason, self-reinforced composite systems contain identical basic materials in regards to the reinforcement and matrix phases. Owing to this material purity, the recycling behavior is simple and unparalleled.

Conventionally, self-reinforced thermoplastics are processed into composite systems using layered textiles, in particular using tape fabrics and fleece systems. In literature, information about hot compaction is focused on mono- [3] and coextruded $[1,12]$ thermoplastic textile systems. Moreover, in the case of monoextruded textile composite systems, the literature recommends alternately layering low-melting coupling agent films to improve the adhesive strength of the composite [15]. Publications concerning the direct processing of layered, thermoplastic film systems into composites using the hot compaction process do not exist at present. Thus, it is necessary to gain a comprehensive understanding of the hot compaction of pure film systems experimentally. The essential difference between film systems and porous textiles lies in the sealed surface structure. Consequently, this additional factor of influence, namely, that of lower air displacement in the volume between the dense film layers, must be taken into account during hot compacting.

In contrast, an even distribution of the pressing force on the stacked films during compacting is positive. Fabrics would display locally differing pressure distributions due to their crossover points. In addition, owing to the fact that films lack the wavy structure of threads, a direct application of force in the composite under loading is possible. The inexpensive manufacture of the basic material is a large advantage when using film composite systems. In comparison to tape fabrics, cutting the films to thin tapes, and processing them into textiles in a weaving process are unnecessary steps. Thus, additional production steps are avoided, and expenses are saved.

Due to the fact that monoaxially stretched films display a strong anisotropy owing to their orientation, they are only limitedly suitable for practical application in film composite systems. One means to compensate this dependency on orientation is to layer the monoaxially stretched films while taking the varying orientation degrees of quasi-isotropic composites into account, as is done in fiber composite technology. Furthermore, the employment of biaxially oriented, semifinished film products increases the mechanical properties orthogonally to the direction of stretching.

In this paper, the hot compaction method is exclusively used for layered films composite systems. Here, monoextruded basic films, which are either stretched or nonstretched, are combined with coextruded coupling agent films. Two different film composite types are hot compacted with nonstretched and monoaxially stretched basic films using three differing process settings. Due to the specifications of the existing stretching line, the fundamental studies in this paper will be done with monoaxially stretched films. The main advantage to use the own stretching line is the high process transparency, such as a precise knowledge about the stretching temperature and the stretching rate during processing. The influence of the processing parameters on the composite properties is analyzed using quasi-static examination methods, and is, subsequently, interpreted. By means of basic investigations, first findings concerning hot compacted film composites alternately layered with coupling agent films are shown.

\section{Experimental}

In the following chapter, the film systems used in this paper are described. We produced nonstretched and stretched basic films ourselves, while our cooperation partner provided coextruded coupling agent films with low-melting external layers. In total, two differently configured film composite systems were manufactured. Their shared property is the alternately layered coupling agent films. One composite configuration thereby combines the nonstretched basic films with alternately layered coupling agent films, while the second configuration employs stretched basic films.

2.1. Applied Materials. The polypropylene Domolen 1102J, which is used for the basic films, is a homopolymer for extrusion applications. The main applications are thermoformed parts, yarns, monofilaments, and strapping. For the coupling agent, a $20 \mu \mathrm{m}$ thick, three-layer, coextruded film with a sealing polymer in the external layers and a homopolymer in the core is used. The homopolymer of the coupling agent film is a polypropylene, type Moplen HP522H, produced by Lyondellbasell. The sealing polymer in the external layers is a polyolefine, type Adsyl 5C39F, with a seal initiation temperature of $105^{\circ} \mathrm{C}$. The properties are shown in Table 1. 
TABLE 1: Properties of the applied materials.

\begin{tabular}{lccc}
\hline & Basic film & \multicolumn{2}{c}{ Coupling agent film } \\
& Domolen 1102J & Moplen HP522H & Adsyl 5C39F \\
\hline MFR [ISO 1133] & $2.5 \mathrm{~g} / 10 \mathrm{~min}$ & $2.0 \mathrm{~g} / 10 \mathrm{~min}$ & $5.5 \mathrm{~g} / 10 \mathrm{~min}$ \\
Tensile modulus of elasticity [ISO 527-3] & $1450 \mathrm{MPa}$ & $1500 \mathrm{MPa}$ & $280 \mathrm{MPa}$ \\
Tensile yield stress [ISO 527-3] & $34 \mathrm{MPa}$ & $34 \mathrm{MPa}$ & $14 \mathrm{MPa}$ \\
Vicat softening temperature [ISO 306] & $154^{\circ} \mathrm{C}$ & $152^{\circ} \mathrm{C}$ & $107^{\circ} \mathrm{C}$ \\
\hline
\end{tabular}

2.2. Manufacture of Films. The manufacture of the polypropylene film, type Domolen 1102J, was carried out in a processing laboratory of the University of Paderborn. The material was plasticized in a single-screw extruder (ESDE 130-33) with cylinder wall temperatures ranging from $160^{\circ} \mathrm{C}$ to $180^{\circ} \mathrm{C}$ and a screw rotation speed of $100 \mathrm{U} / \mathrm{min}$. It was formed using a wide nozzle with a gap width of $0.5 \mathrm{~mm}$ at $180^{\circ} \mathrm{C}$. The film is taken-off and flattened using a chill rolling system (CR 136/350 by Dr. Collin), rotating $6.5 \mathrm{~m} / \mathrm{min}$ at a chill-roll temperature of $20^{\circ} \mathrm{C}$. Thus, $200 \mu \mathrm{m}$ thick polypropylene films are produced. After the production of flat films, monoaxial stretching was carried out. The monoaxial stretching line (Figure 3) belongs to the Teach-Line series designed by Dr. Collin. It is a single column stretching system that employs the so-called short stretching gap method. The film passes through the system from the right to the left. The rollers of the second unit are set at a higher speed than those in the first unit, creating the desired stretching ratio. The film is preheated on five rollers and, due to the speed difference, stretched between the sixth and seventh roller. The rollers seven, eight, and nine temper the film and rollers numbers ten and eleven cool it. The rollers are heated by means of three tempering zones. For this purpose, the rollers three and seven to nine are drawn through water and the rollers four to six are drawn through oil (Marlotherm SH) to temper them. Cooling water runs through rollers ten and eleven at a temperature of approximately $25^{\circ} \mathrm{C}$.

The speed of the first roller unit designates variable $v_{1}$. Accordingly, variable $v_{2}$ represents the speed of the second unit. The stretching ratio (SR) is the quotient of the two speeds $v_{1}$ and $v_{2}$ as follows:

$$
\text { stretching ratio } \mathrm{SR}=\frac{l_{0}+\Delta l}{l_{0}}=1+\varepsilon=\frac{v_{2}}{v_{1}} .
$$

The results for the monoaxial stretching of amorphous polycarbonate film and the influence of the processing parameter on the stretching process were shown in [9]. An anisotropy of the mechanical properties is induced in the film by means of monoaxial stretching. This was examined in [16].

A stretching temperature of $160^{\circ} \mathrm{C}$ was used for the monoaxial stretching of polypropylene film and the film was stretched using a stretching ratio of 3 . After stretching, the polypropylene film's final thickness is approximately $100 \mu \mathrm{m}$.

\subsection{Manufacture of Laminates in a Hot-Compaction Process.} The first pretests with directly layered, monoextruded PPfilm only achieved limited success in regards to the mechanical properties. For this reason, an alternating laminate

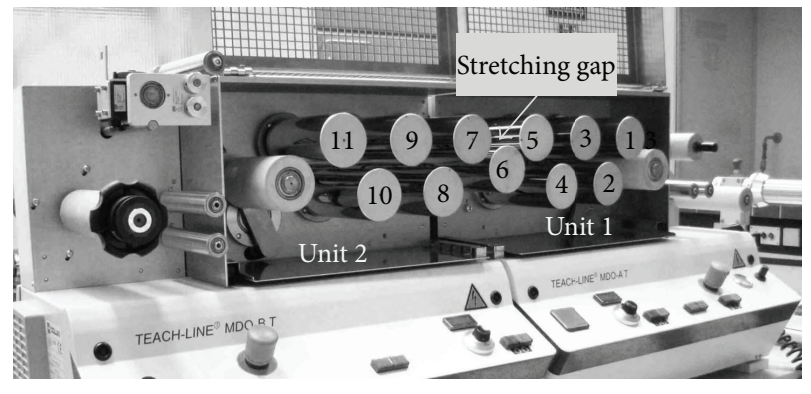

FIGURE 3: Monoaxial stretching line.

structure will be used. Two different layered film composites are produced, which share an alternating layered structure. The bases for the manufacture of layered PP-film composites are predesigned flaccid film strips that were produced using the manufacturing process described in Chapter 2.2. Owing to the fact that the thicknesses of the employed nonstretched and stretched basic films vary significantly, two differing layering concepts are necessary for the manufacture of approximately $2 \mathrm{~mm}$ thick laminates. 18 layers of the $1: 3$ stretched Domolen film (thickness of single film $0.1 \mathrm{~mm}$ ) are layered in an alternated manner with 17 layers of the low-melting coupling agent film, which generates the matrix phase in the composite. A further layered film structure consisting of 8 layers of extruded, nonstretched PP-film (thickness of a single film $0.2 \mathrm{~mm}$ ) with 7 layers of coupling agent film is layered in between functions as a reference. All films are layered uniformly in the direction of production (MD). Table 2 illustrates the layering concepts for the employed layered film composite systems.

Both layered composite systems are processed in a hotcompaction process using three different processing settings, in order to verify direct influences of the degree of stretching on the processing settings. The selection of the process settings is based both on experience using hot compaction for PP composite systems as well as on thermal analyses carried out for the employed film systems; see Chapter 3.2. This means that for each processing setting (I, II, and III) layered composite systems with stretched and others with nonstretched basic films are produced. Especially the composite quality is influenced by the compaction temperature. A low temperature is inadequate for matrix generation, while the directed macromolecules are reoriented at a too high selected compaction temperature. Table 3 shows the compaction parameters of the process settings I to III for the manufacture of film systems in a hot-compaction process. 
TABLE 2: Layering concept for the employed film systems.

\begin{tabular}{lcccc}
\hline Type of film & Film thickness $(\mathrm{mm})$ & Bumber of layers & Coupling agent film & Film size $\left(\mathrm{mm}^{2}\right)$ \\
\hline PP nonstretched & 0.2 & 8 & 7 & $148 \times 500$ \\
PP stretched 1:3 & 0.1 & 18 & 17 & $135 \times 500$ \\
\hline
\end{tabular}

TABLE 3: Processing settings for the processing of alternately layered PP-film systems.

\begin{tabular}{lccc}
\hline Process setting & & Hot-compaction & \\
Cressing time $(\mathrm{s})$ & 120 & Compaction pressure $(\mathrm{MPa})$ \\
\hline I & 165 & 120 & 3 \\
II & 170 & 60 & 1 \\
III & 175 & 1 & 1 \\
\hline
\end{tabular}

The processing of the film systems is carried out on an $800 \mathrm{kN}$ precision hot press LAP 80 manufactured by Gottfried Joos Maschinenfabrik GmbH and CO. KG. The tool employed for hot-compaction consists of press plates (total surface area $500 \times 500 \mathrm{~mm}^{2}$ ) that are tempered by fluid.

Figure 4 depicts the mandatory processing steps for the manufacture of layered composites using a hot-compaction method [17]. In the beginning of processing, the layered stack of films with alternately stacked coupling agent films (see yellow intermediate layer in Figure 4) is placed into the cold tool. Subsequently, the pressing unit is closed in the first processing step, and the pressing force necessary for hotcompaction is built up.

Once this has been completed, the stack of film is tempered to the compaction temperature using the correct pressure. The fitting pressing force is of special significance, because the stack of film is, for the most part, prevented from stretching due to fixation. Therefore, the tendency to shrink when exposed to temperatures, especially those of oriented films, is reduced. As soon as the pressing temperature is reached, the second processing step is initiated. The pressing temperature is kept at a constant level throughout the selected pressing time, in order to enable the development of the matrix in the composite system. Finally, the composite system is consolidated in the third processing step by means of a cooling sequence ( $40 \mathrm{~K} / \mathrm{min}$ averaged) while subjected to the pressing force. After the pressing unit opens automatically, the cooled laminated can be removed.

\subsection{Characterization Techniques and Specimen Preparation}

2.4.1. Preparation of Film Specimens for Tensile Tests. The preparation of the $100 \times 15 \times 0.1 \mathrm{~mm}^{3}$ sized square specimens is carried out using a stamp with the required geometry according to DIN EN ISO 527-3, because this method guarantees a good quality of the specimen marginal area. The tensile tests were performed in accordance with DIN EN ISO 527-3 on a Zwick universal testing machine, type 1446. For each testing point, a series of six tensile specimens were examined. The machine is equipped with a $1 \mathrm{kN}$ measuring cell and a hydraulic clamping device. The testing speed was $v$ $=50 \mathrm{~mm} / \mathrm{min}$, the determination of the modulus of elasticity is calculated between $0.05 \%$ and $0.25 \%$ deformation at a testing speed of $v_{E}=1 \mathrm{~mm} / \mathrm{min}$.

2.4.2. Preparation of Composite Specimens for Tensile Tests. The specimens which correspond to DIN EN ISO 527-4 were extracted from the hot-compacted laminate strips for the determination of the tensile modulus of elasticity. The preparation of these $160 \times 20 \times 2 \mathrm{~mm}^{3}$ sized specimens with a width of $10 \mathrm{~mm}$ in the testing zone is carried out using a multistep, increasingly precise machining method.

The determination of the tensile properties is achieved using a quasi-static tensile test that corresponds with DIN EN ISO 527-4 for isotropic and anisotropic fiber reinforced plastic composite materials. The test bars used for tensile testing are tested along their main axis at a constant speed until failure occurs. The tensile tests were completed on a Zwick universal testing machine, type 1474. This machine is equipped with a $100 \mathrm{kN}$ measuring cell and a hydraulic clamping device. The essential bases for assessment in this contribution are the tensile modulus of elasticity $E_{t}$ and the tensile strength $\sigma_{M}$ of both composite systems exclusively. The testing speed $v=10 \mathrm{~mm} / \mathrm{min}$ was selected in accordance with DIN EN ISO 527-4. The determination of the modulus of elasticity is normatively calculated between $0.05 \%$ and $0.25 \%$ stretching at a testing speed of $v_{E}=1 \mathrm{~mm} / \mathrm{min}$. All tests are carried out in standard atmosphere conditions in accordance with DIN EN ISO 291 (characteristic 23/50).

2.4.3. Differential Scanning Calorimetry (DSC). In order to determine the thermal properties of the film systems, DSC analyses were carried out in accordance with DIN EN ISO 11357-1. The employed testing instrument is a DSC Q1000 V9.0 Build 275 manufactured by TA Instruments. The DSC analyses were carried out with specimen weights of approximately $6 \mathrm{mg}$ between $0^{\circ} \mathrm{C}$ and $250^{\circ} \mathrm{C}$ at a heating rate of $10 \mathrm{~K} / \mathrm{min}$.

\section{Results and Discussion}

3.1. Tensile Properties of the Basis Films. The basic properties of the employed films are shown in Figure 5 in the direction of stretching or extrusion (MD) and in the transverse direction 


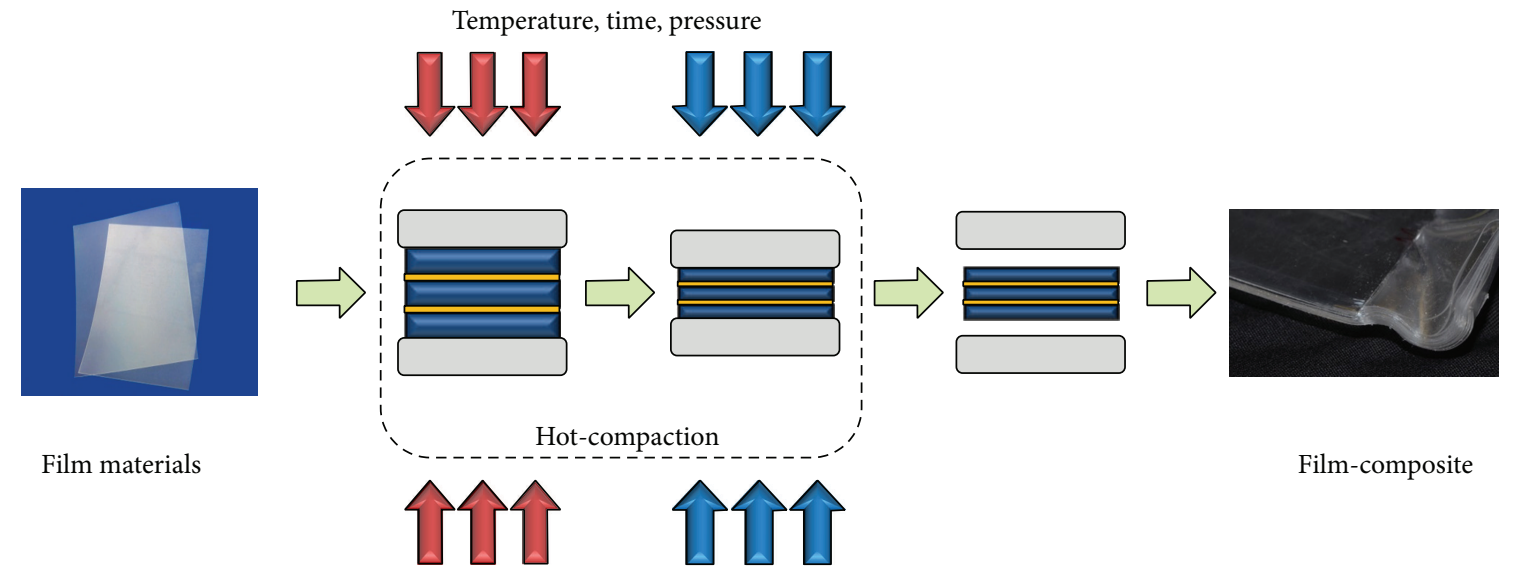

FIGURE 4: Processing steps for the manufacture of alternately layered PP-film composite systems.

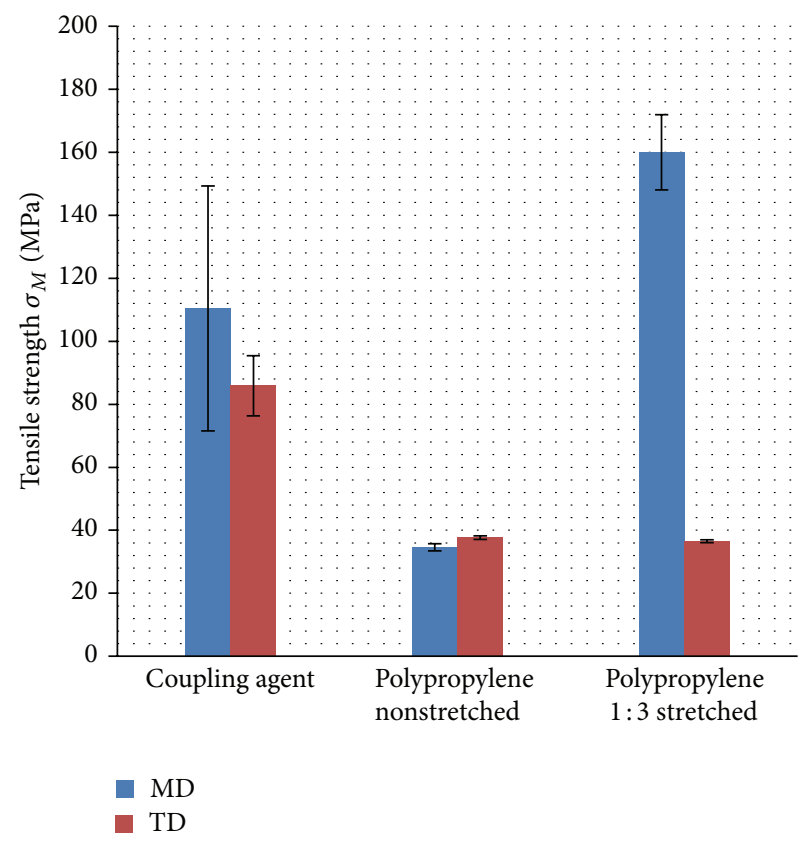

(a)

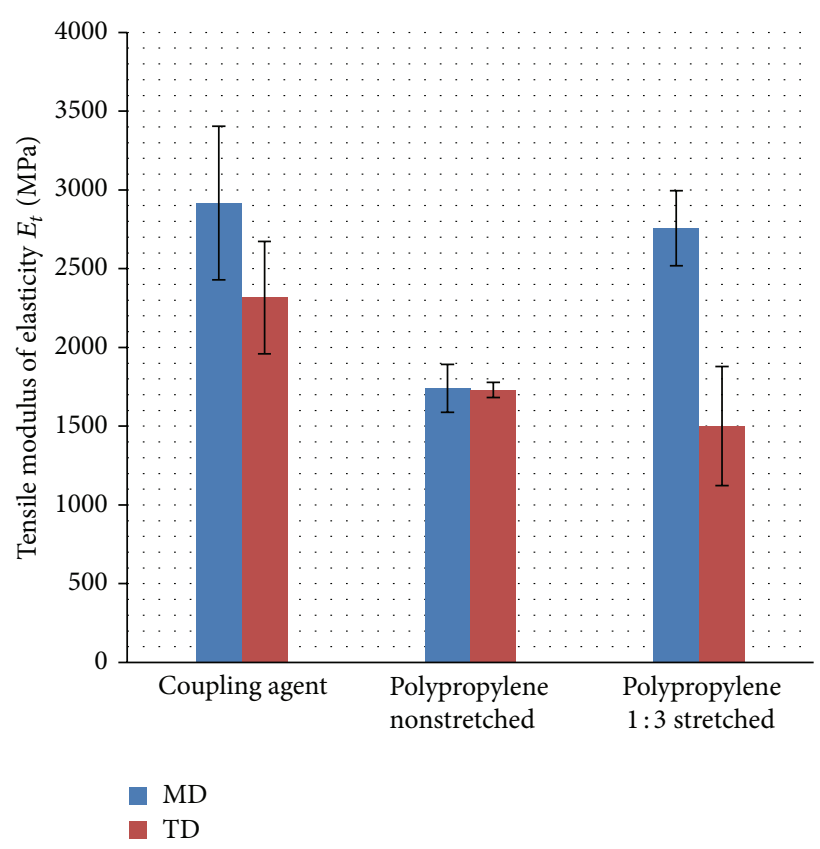

(b)

FIgure 5: (a) Tensile strength and (b) tensile modulus of the employed films in MD and TD.

(TD). The stretching process leads to an orientation in MD, which, in turn, results in a higher strength (Figure 5(a)). The coupling agent film and the stretched polypropylene film have an essentially higher tensile strength in MD. In $\mathrm{TD}$, the tensile strength remains unchanged at the same level as polypropylene film that has not been stretched. In Figure 5(b), the tensile modulus of elasticity is illustrated. They are also higher in the direction of orientation rather than in the direction transverse to the orientation. The modulus of elasticity of PP that has not been stretched is identical for both the MD and TD.

3.2. Thermal Analyses of the Basic Films by Differential Scanning Calorimetry (DSC). Figure 6 depicts the measured heat flow above the temperature for the coupling agent film, by a specimen weight of $5.95 \mathrm{mg}$. In the first heating cycle the melt temperature of the stretched homopolymer is $163^{\circ} \mathrm{C}$. At $155^{\circ} \mathrm{C}$, the melt peak of the sealing polymer is visible. In contrast, the second heating cycle shows the DSC measurement of the completely reoriented coupling agent polymer with a lower melt peak at $161^{\circ} \mathrm{C}$.

The heat flow is shown in Figure 7 above the temperature for nonstretched and stretched polypropylene film. The melt temperature of PP-film that has not been stretched equals $163^{\circ} \mathrm{C}$ in the first heating cycle. Stretched PP-film displays a melt peak at $165^{\circ} \mathrm{C}$. Stretching increases the degree of crystallization, causing the melt point to shift to higher temperatures [18]. In contrast, the melt peaks of the second heating cycles for the reoriented nonstretched and stretched $\mathrm{PP}$-films are approximately equal to $161^{\circ} \mathrm{C}$. 


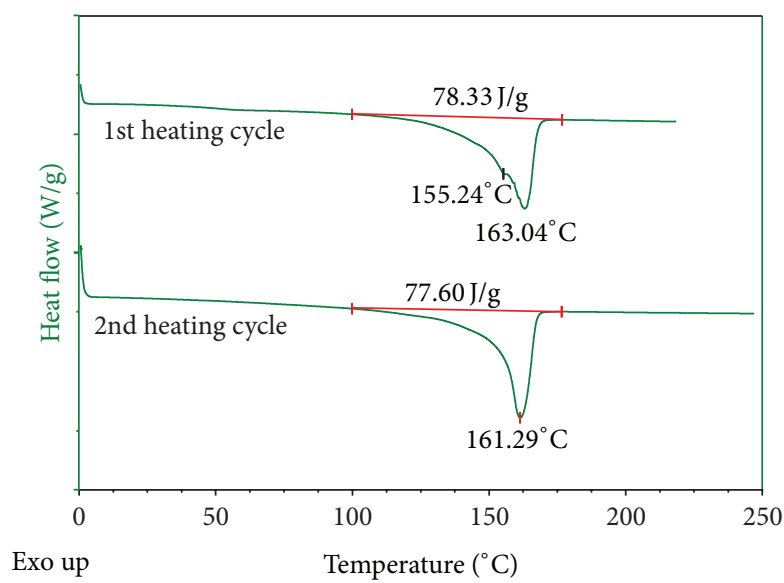

FIGURE 6: DSC analysis of coupling agent film.

3.3. Tensile Properties of Film Bases PP-Composites. Figure 8 illustrates the tensile modulus of elasticity of PP-film systems with stretched and nonstretched basic films determined using tensile tests. The modulus of elasticity of the PP-films in a nonstretched and 1:3 stretched state is used as a direct reference for the hot-compacted composite systems.

The tensile modulus of elasticity $E_{t}$ of the nonstretched composites ranges from approximately 1700 to $2200 \mathrm{MPa}$. A definite influence of the processing settings (processes I to III) is visible, especially in correlation with an increasing processing temperature. The composites manufactured according to processes I and II achieve a 20\% higher stiffness in comparison to nonstretched basic film. The combination of nonstretched basic films and stretched coupling agent films results in a stiffness increasing influence. The high processing temperature used in process III initiates a reversal of the orientation of the directed macromolecules, leading to a reduction of the composite stiffness back to the level of nonstretched basic films.

In contrast to nonstretched composite systems, the composites containing films stretched at a ratio of 3 display a stiffness increase of approximately $29 \%$ on average. The tensile modulus of elasticity of the stretched composite systems shows a range from around $2600 \mathrm{MPa}$ to $3000 \mathrm{MPa}$. The influence of the process conditions on the composite stiffness can be verified by the continuously decreasing values as the exposure to temperature increases. The higher relaxation potential of the oriented films causes the values to reduce below the reference stiffness when exposed to a higher processing temperature in process III.

Figure 9 shows the tensile strengths of stretched and nonstretched layered film composites that were determined experimentally. It also compares these values to those of the employed semifinished basic films. The developments of the tensile strengths in processes I to III are analogous to and reproducible like the stiffness values shown in Figure 8.

The tensile strengths of nonstretched composite systems (processes I to III) are restricted to a relatively small window. They display a spectrum of merely $35 \mathrm{MPa}$ to $39 \mathrm{MPA}$.
Composites compacted at low and medium processing temperatures (processes I and II) display a minimal increase in tensile strength by approximately $4 \mathrm{MPa}$ in comparison to process III and nonstretched basis film.

Due to their macromolecular orientation, the stretched layered film composites achieve an enormous increase in strength. Handling materials gently when processing after process I leads to an increase in strength of about $78 \%$ when directly comparing the values to those of a composite system containing film that has not been stretched. However, it has also been observed that the stretched film composites react remarkably more sensitive when exposed to heat in regards of their strength. Thus, the composite strengths measured after processes II and III are visibly lower than that of the basic stretched film. The increase in temperature by $10^{\circ} \mathrm{C}$ between process I and III causes a reduction of the strength by $57 \%$.

\section{Conclusion}

In this paper, the hot compaction method was employed for layered film composite systems, which combine stretched and nonstretched monoextruded basic films with coextruded coupling agent films. Stretching basic films monoaxially leads to an orientation of the macromolecules in the direction of shaping, and it is reflected in an increase of the strength and stiffness. By means of DSC analyses, it was verified that the melting point of the coextruded external layers of the coupling agent film equals $155^{\circ} \mathrm{C}$. In contrast, the stretched PP-film reaches its melting point at $165^{\circ} \mathrm{C}$. In doing so, it is possible to achieve a good composite strength in a hot compaction process using low processing temperatures. Simultaneously, the previously implemented orientation and the accordingly induced good mechanical properties of the stretched basic films can be, for the most part, preserved.

By means of the hot compaction process, evidence was obtained that the alternating layered structure of reinforcement films with low-melting coupling agent films enables a remarkable increase of the tensile values, particularly in the case of stretched film composite systems. However, because stretched films possess a higher orientation degree in the macromolecules, their affinity to relax when exposed to heat also rises. The temperature window is thus restricted to a few degrees Celsius. For this reason, high precision of system equipment is necessary when processing oriented film composites in a hot compaction process. In particular, large fluctuations regarding temperature control are not allowed to occur.

It was shown that semifinished sheets can be produced by an alternating layered structure of PP-films with coupling agent films, whose mechanical properties are comparable with the properties of the stretched basic films. Since stretched semifinished sheets in this thickness cannot be established due to the high relaxation times, the hot compaction process offers a good alternative to the use of reinforcing fillers, such as glass fibers.

Especially the composite system which consists of stretched basic films displays high potential for property gradation. By coupling the processing parameters, that is, 

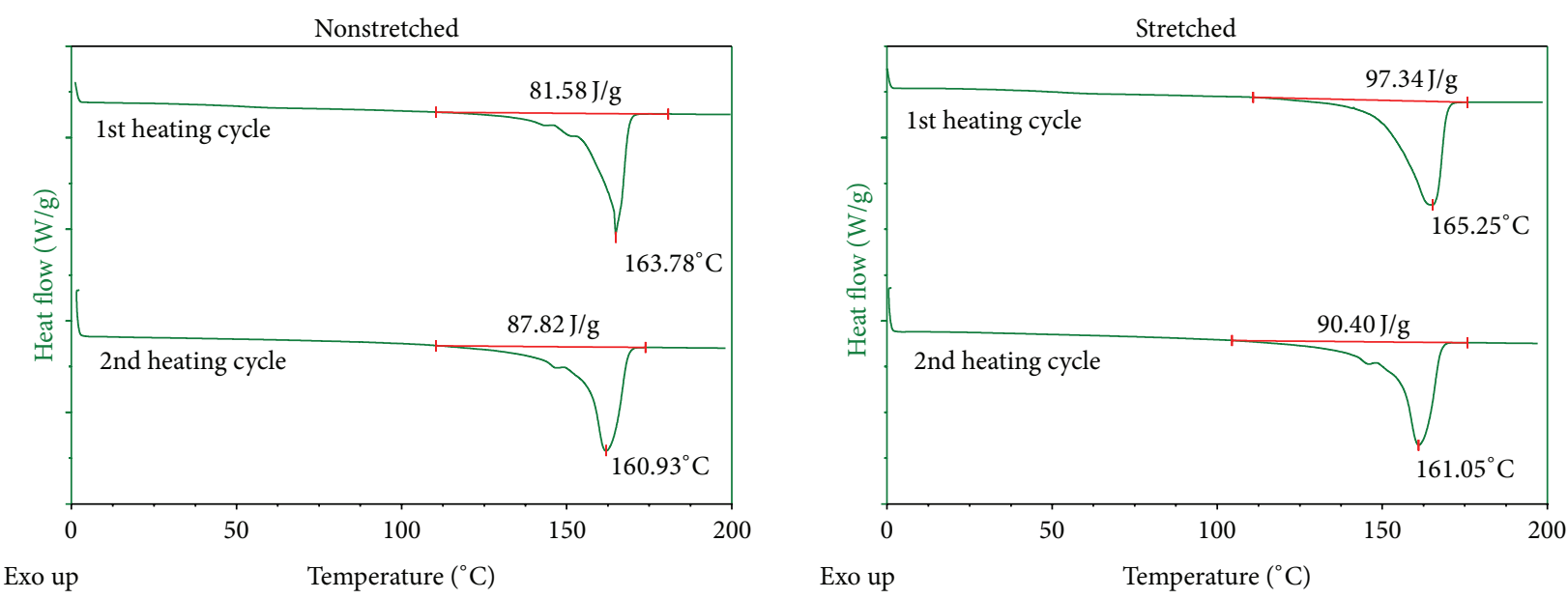

FIGURE 7: DSC analyses of nonstretched and 1:3 stretched PP-film.

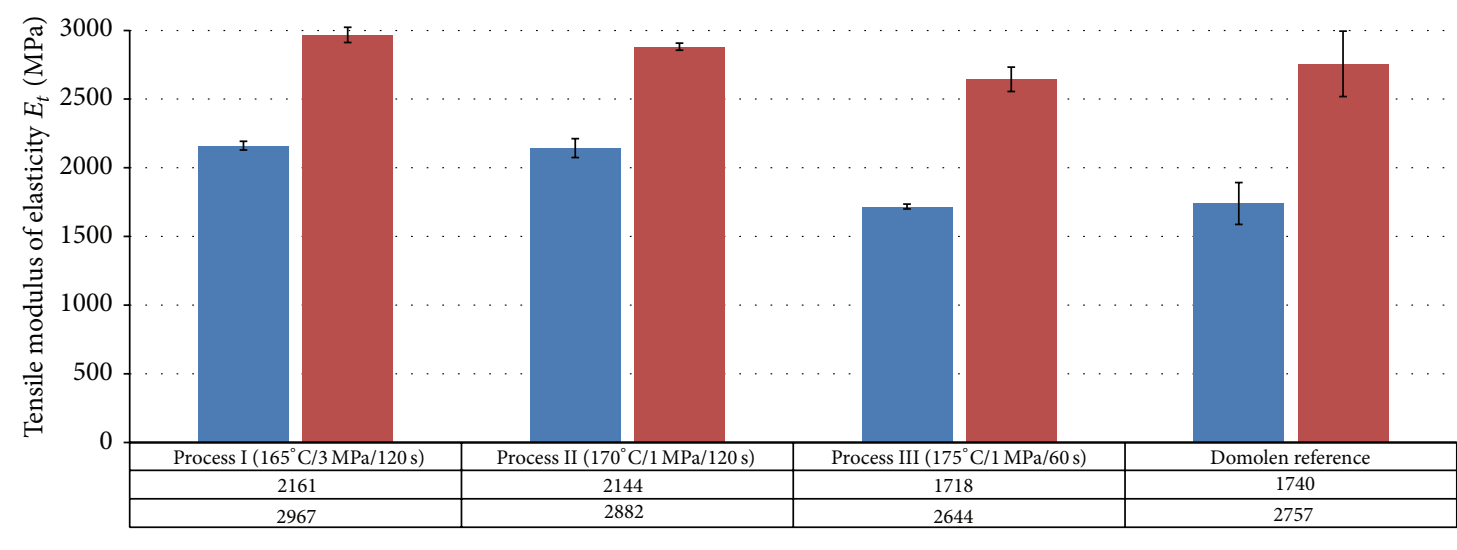

- Nonstretched

Tabular values (MPa)

- Stretched

FIGURE 8: Modulus of elasticity in correlation with the processing settings of stretched and nonstretched film composite systems in comparison to the basic film material.

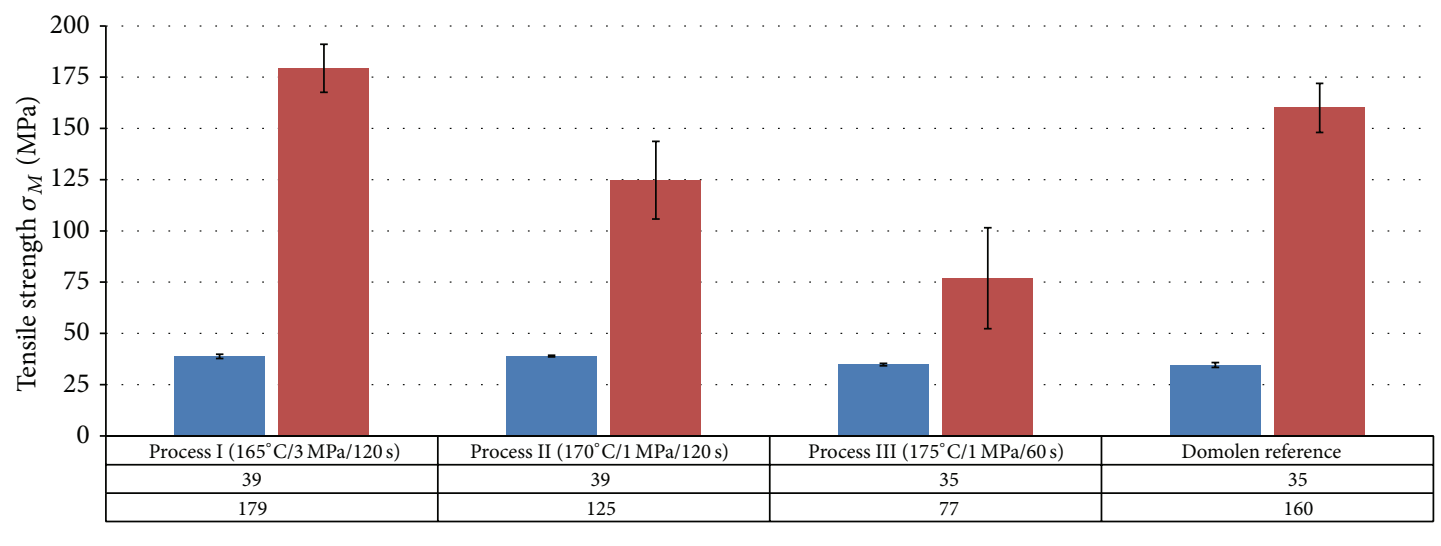

Tabular values $(\mathrm{MPa})$

- Nonstretched

- Stretched

FIGURE 9: Tensile strengths in correlation with the processing settings of stretched and nonstretched film composites systems in comparison to the basic film material. 
pressing temperature, force, and time, it is possible to achieve a specific tailoring of the mechanical properties of the composite during the hot compaction process. In regards to the tensile strengths, a significant effect is visible in correlation with an increasing processing temperature.

\section{Conflict of Interests}

The authors declare that they have no direct financial relation and there is no conflict of interests regarding the publication of this paper for any of the authors.

\section{Acknowledgments}

This paper is based on investigations carried out in the Collaborative Research Centre CRC/TRR 30, subprojects A5 and A8, which is kindly supported by the German Research Foundation (DFG). Furthermore, we would like to express our gratitude to Brückner Maschinenbau $\mathrm{GmbH}$ for providing the coupling agent film which was produced at their pilot plant.

\section{References}

[1] B. Alcock, N. O. Cabrera, N.-M. Barkoula, C. T. Reynolds, L. E. Govaert, and T. Peijs, "The effect of temperature and strain rate on the mechanical properties of highly oriented polypropylene tapes and all-polypropylene composites," Composites Science and Technology, vol. 67, no. 10, pp. 2061-2070, 2007.

[2] D. Bhattacharyya and S. Fakirov, Synthetic Polymer-Polymer Composites, Carl Hanser, Munich, Germany, 2012.

[3] P. J. Hine, I. M. Ward, N. D. Jordan, R. Olley, and D. C. Bassett, "The hot compaction behaviour of woven oriented polypropylene fibres and tapes. I. Mechanical properties," Polymer, vol. 44, no. 4, pp. 1117-1131, 2003.

[4] S. Hess, A. Ries, P. Kersting, and H. P. Heim, "Efficient spatial and temporal modelling of material temperatures within selfreinforced polypropylene sheets during IR radiation," Procedia CIRP, vol. 9, pp. 49-54, 2013.

[5] D. Biermann, H. P. Heim, B. Rohde, M. Tiffe, A. Ries, and A. Zabel, "Examinations of the machining behaviour of selfreinforced, thermo-mechanically graded polypropylene composites," in Proceedings of the 34th International Technical Conference \& Forum SAMPE Europe (SEICO '13), pp. 139-144, Paris, France.

[6] T. Bárány, J. Karger-Kocsis, and T. Czigány, "Development and characterization of self-reinforced poly(propylene) composites: carded mat reinforcement," Polymers for Advanced Technologies, vol. 17, no. 9-10, pp. 818-824, 2006.

[7] D. Paßmann, Prozessinduzierte gradierung eigenverstärkter polypropylen-faserverbunde beim Heißkompaktieren und umformen [M.S. dissertation], University of Kassel, 2009.

[8] G. W. Ehrenstein, Polymerwerkstoffe: Struktur, Eigenschaften, Anwendung, Hanser, Auflage, München, Germany, 2011.

[9] H. P. Heim, B. Rohde, and A. Ries, "Morphology-propertyrelationship of thermo-mechanically graded self-reinforced polypropylene composites," in Proceedings of the 29th Annual Meeting of Polymer Processing Society, pp. S22-243, Nuremberg, Germany, July 2013.
[10] A. Wibbeke and V. Schöppner, "Comparison of stretched polycarbonate films produced on a stretching line and a tender frame," Polymer Engineering and Science, 2013.

[11] J. Rössler, H. Harders, and M. Bäker, Mechanisches Verhalten der Werkstoffe, Fieweg+Teubner, Auflage, Wiesbaden, Germany, 2008.

[12] T. Peijs, "Composites for recyclability," Materials Today, vol. 6, no. 4, pp. 30-35, 2003.

[13] S. Fakirov, "Nano- and microfibrillar single-polymer composites: a review," Macromolecular Materials and Engineering, vol. 298, pp. 9-32, 2013.

[14] Á. Kmetty, T. Bárány, and J. Karger-Kocsis, "Self-reinforced polymeric materials: a review," Progress in Polymer Science, vol. 35, no. 10, pp. 1288-1310, 2010.

[15] P. J. Hine, A. P. Unwin, and I. M. Ward, "The use of an interleaved film for optimising the properties of hot compacted polyethylene single polymer composites," Polymer, vol. 52, no. 13, pp. 2891-2898, 2011.

[16] A. Wibbeke, V. Schöppner, and R. Mahnken, "Experimental investigations on the induced anisotropy of mechanical properties in polycarbonate films," ISRN Materials Science, vol. 2013, Article ID 649043, 8 pages, 2013.

[17] I. M. Ward and P. J. Hine, "The science and technology of hot compaction," Polymer, vol. 45, no. 5, pp. 1413-1427, 2004.

[18] B. Monasse and J. M. Haudin, "Thermal dependence of nucleation and growth rate in polypropylene by non isothermal calorimetry," Colloid \& Polymer Science, vol. 264, no. 2, pp. 117122, 1986. 

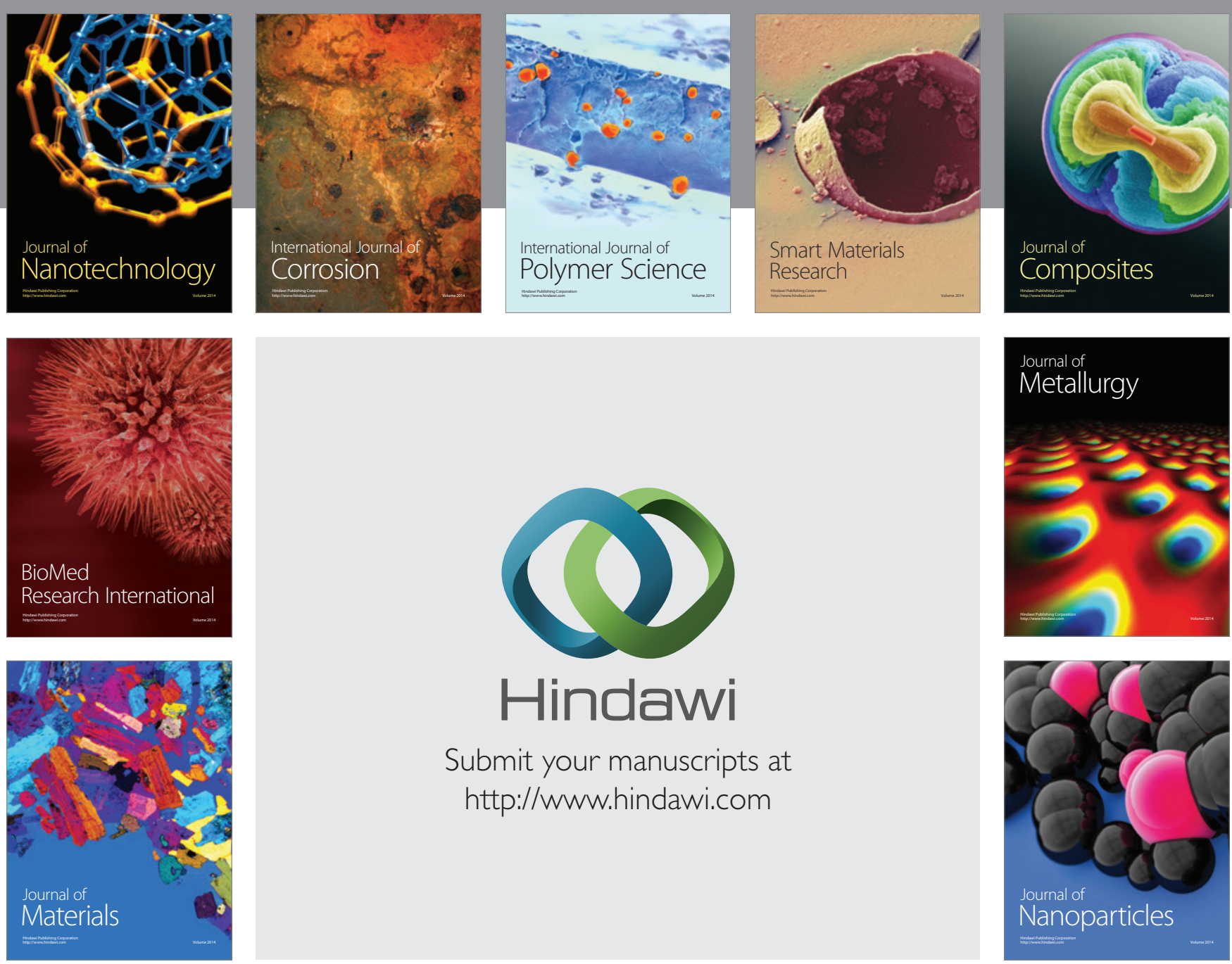

Submit your manuscripts at http://www.hindawi.com
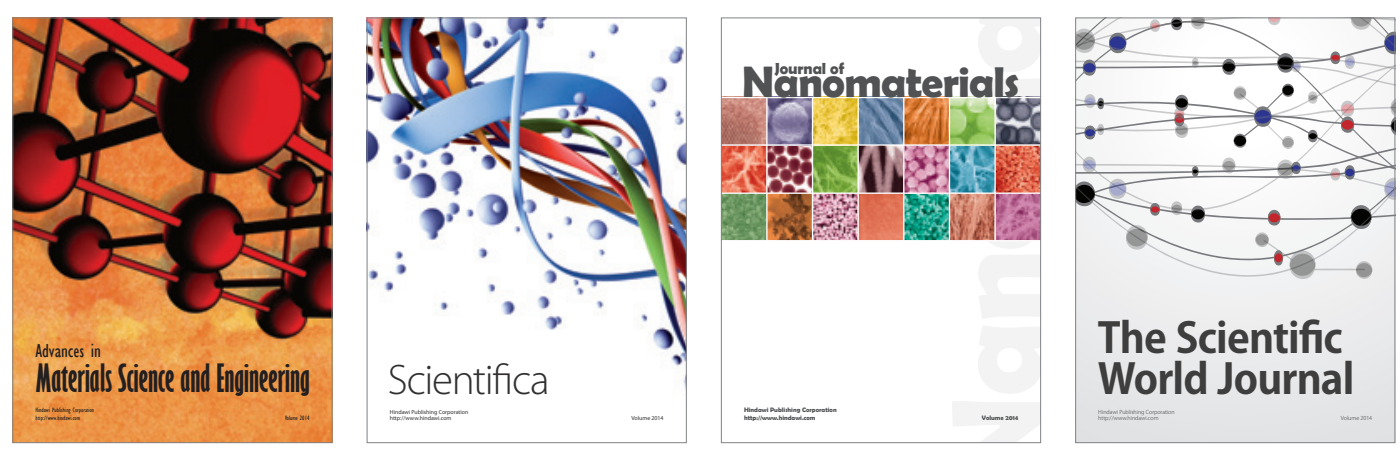

\section{The Scientific World Journal}
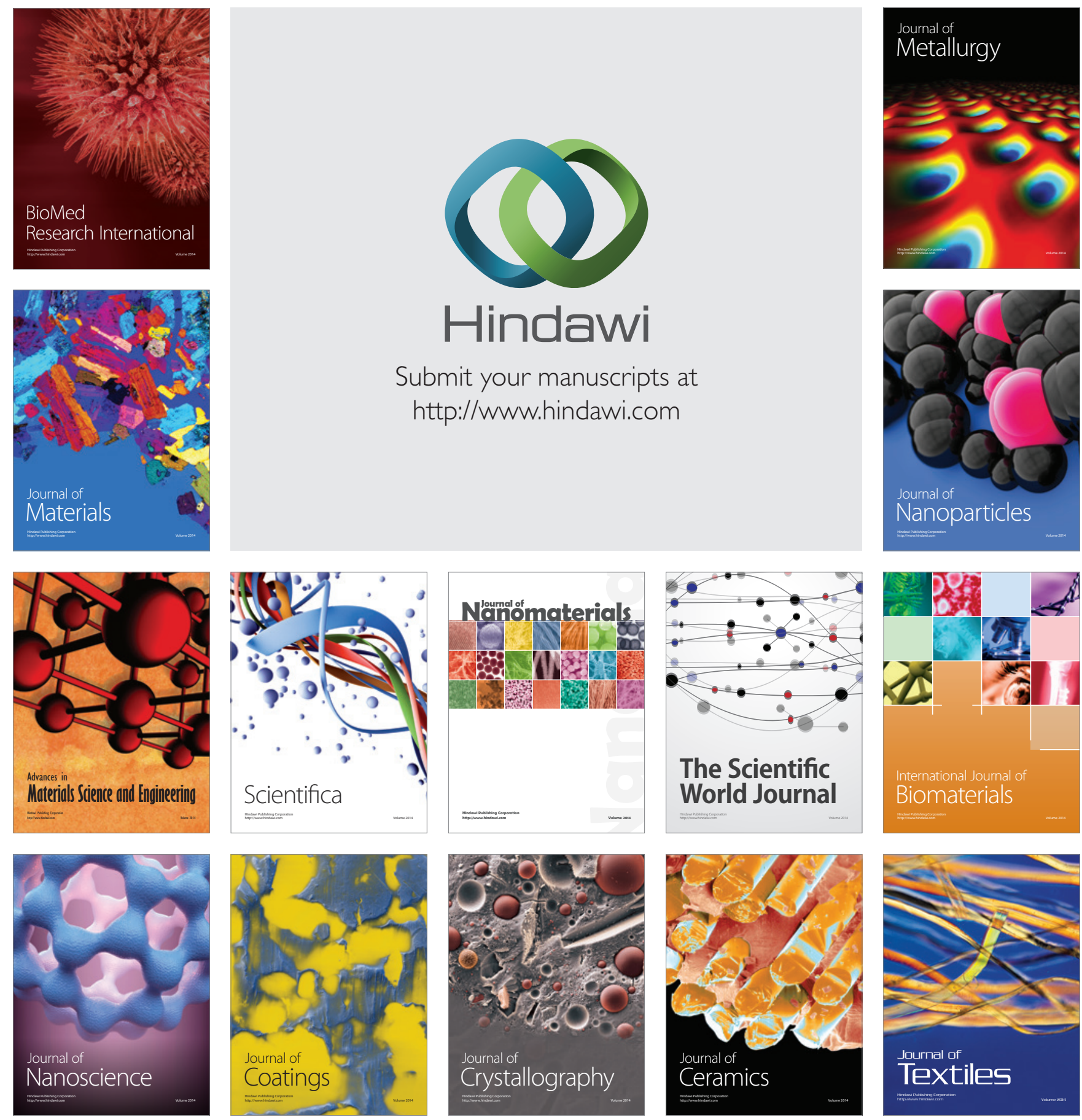